\title{
DISPROOF OF A COEFFICIENT ESTIMATE RELATED TO BAZILEVIC FUNCTIONS
}

\section{MASSOUd JAHANGIRI}

A coefficient estimate for powers of a class of Bazilevic functions obtained by M.M.

Elhosh, is disproved and some sharp bounds are given.

Suppose that $m$ is a positive integer. For functions $f(z)=z+a_{2} z^{2}+a_{3} z^{3}+\cdots$ analytic in the open unit disk $U=\{z:|z|<1\}$ and for $\phi(z)=z /(1-z)$ we write (see also[6] and [7])

$$
\left\{f\left(z^{m}\right)\right\}^{1 / m}=\sum_{n=0}^{\infty} a_{n}(m) z^{m n+1} \text { and }\left\{\phi\left(z^{m}\right)\right\}^{1 / m}=\sum_{n=0}^{\infty} b_{n}(m) z^{m n+1}
$$

so that

$$
\begin{aligned}
& a_{0}(m)=1, a_{1}(m)=\frac{1}{m} a_{2}, a_{2}(m)=\frac{1}{m}\left(a_{3}-\frac{m-1}{2 m} a_{2}^{2}\right), \\
& b_{0}(m)=1 \text { and } \\
& b_{n}(m)=\frac{(1+m)(1+2 m) \cdots(1+(n-1) m)}{(n !) m^{n}} ; n=1,2, \cdots .
\end{aligned}
$$

For $0<\alpha<\infty$ let $B(\alpha)$, called Bazilevic of type $\alpha$, denote the class of functions $f(z)=z+a_{2} z^{2}+\cdots$ analytic in $U$ and satisfying

$$
f(z)=\left\{\alpha \int_{0}^{z} g^{\alpha}(t) p(t) t^{-1} d t\right\}^{1 / \alpha}
$$

where $g(z)$ is starlike, that is $\operatorname{Re}\left\{z g^{\prime}(z) / g(z)\right\}>0$ and $p(z)$ is of positive real part with $p(0)=1$.

It has been proved by many authors including Bazilevic [1] that the functions in $B(\alpha)$ are univalent. (See Bernardi [2].) The coefficient problem for $f(z)$ in $B(\alpha)$ has been settled by Leach [8] (also see Math. Rev. 83C: 30015). For more references on the coefficients of Bazilevic functions see [2].

Received 25 September 1989

Copyright Clearance Centre, Inc. Serial-fee code: 0004-9729/90 \$A2.00+0.00. 
Elhosh [4] considered the subclass $B_{1}(\alpha)$ of $B(\alpha)$ for which $p(z) \equiv 1$. Note that $B_{1}(1)$ is the class of convex functions, that is $f(z)$ is convex if and only if $z f^{\prime}(z)$ is starlike. (See [5] p.115.) Elhosh ([4], Theorem 4) stated the following: Let $f(z) \in$ $B_{1}(\alpha)$, let $0<\alpha \leqslant 1$, and let $F(z)=\left\{f\left(z^{2}\right)\right\}^{1 / 2}=z+c_{3} z^{3}+c_{5} z^{5}+\cdots$. Then for $n \geqslant 1$, we have

$$
\left|C_{2 n+1}\right| \leqslant \frac{1}{2 n+1}
$$

In this paper we show that (4) is not true when $1 / 2<\alpha \leqslant 1$.

Counter-EXample 1. Let $\alpha=1$. Consider the extremal function $\phi(z)=z /(1-z) \epsilon$ $B_{1}(1)$. Then for $F(z)=\left\{\phi\left(z^{2}\right)\right\}^{1 / 2}$ we obtain from (2) that

$$
b_{n}(2)=\frac{3 \cdot 5 \cdot 7 \cdots(2 n-1)}{(n !) 2^{n}} .
$$

It is easy to see that $b_{n}(2)>1 /(2 n+1)$.

Counter-EXample 2. Suppose that $f(z)=z+a_{2} z^{2}+\cdots$ belongs to $B_{1}(\alpha)$; $0<\alpha<\infty$. Then for $F(z)=\left\{f\left(z^{m}\right)\right\}^{1 / m}$ given by (1) we have the sharp bounds

$$
\left|a_{1}(m)\right| \leqslant \frac{2 \alpha}{m(\alpha+1)}
$$

and

$$
\left|a_{2}(m)\right| \leqslant \frac{\alpha}{m(\alpha+2)}\left[1+\frac{2 \alpha(\alpha+m+2)}{m(\alpha+1)^{2}}\right] .
$$

For $m=2,(5)$ and (6) are sharper than (4) when $0<\alpha<1 / 2$ and disprove (4) when $1 / 2<\alpha \leqslant 1$.

For $f(z) \in B_{1}(\alpha)$ and for the starlike functions $g(z)$ we have

$$
f(z)=\left\{\alpha \int_{0}^{z} g^{\alpha}(t) t^{-1} d t\right\}^{1 / \alpha}
$$

Write

$$
\frac{z g^{\prime}(z)}{g(z)}=p(z)=1+p_{1} z+p_{2} z^{2}+\cdots
$$

where $\operatorname{Re} p(z)>0$. Note that $\left|p_{n}\right| \leqslant 2$. (See $[5]$, p.80.) 
Let $F(z)=\left\{f\left(z^{m}\right)\right\}^{1 / m}$. We obtain from (8), (7) and (1) that

$$
a_{1}(m)=\frac{\alpha}{m(\alpha+1)} p_{1}
$$

and

$$
a_{2}(m)=\frac{\alpha}{2 m(\alpha+2)}\left[p_{2}+\frac{\alpha(m+\alpha+2)}{m(\alpha+1)^{2}} p_{1}^{2}\right] .
$$

Now (5) follows from (9) upon noting that $\left|p_{1}\right| \leqslant 2$. For (6) we obtain from (10) that

$$
\begin{aligned}
\left|a_{2}(m)\right| & =\frac{\alpha}{2 m(\alpha+2)}\left|p_{2}+\frac{\alpha(m+\alpha+2)}{m(\alpha+1)^{2}} p_{1}^{2}\right| \\
& \leqslant \frac{\alpha}{2 m(\alpha+2)}\left[\left|p_{2}\right|+\frac{\alpha(m+\alpha+2)}{m(\alpha+1)^{2}}\left|p_{1}\right|^{2}\right] \\
& \leqslant \frac{\alpha}{m(\alpha+2)}\left[1+\frac{2 \alpha(m+\alpha+2)}{m(\alpha+1)^{2}}\right]
\end{aligned}
$$

where we used the fact that $\left|p_{1}\right| \leqslant 2$ and $\left|p_{2}\right| \leqslant 2$. To show that (5) and (6) are sharp we let $p_{1}=p_{2}=2$ in (9) and (10).

REMARK 1. The functions in $B_{1}(\alpha)$ are related to $\beta$-convex functions; $\alpha=1 / \beta$ (see [3], p.5), which was first introduced by Mocanu [9].

REMARK 2. Using Remark 1, with a little manipulation, we can obtain the estimates (5) and (6) from [3] and [10].

REMARK 3. Szynal and Wajler [11] obtained sharp bounds for the fourth coefficients of $\beta$-convex functions which can be used for $a_{3}(m)$.

REMARK 4 . Finding sharp bounds for $a_{n}(m)$ when $n \geqslant 4$ is more difficult and is an open problem.

\section{REFERENCES}

[1] I.E. Bazilevic, 'On a case of integrability by quadratures of the Loewner-Kufarev equation', Math. Sb. N.S. 37 (79) (1955), 471-476. (Russian) .

[2] S.D. Bernardi, Bibliography of Schlicht functions (Mariner Pub. Co., Tampa, Florida, 1982).

[3] P.J. Eenigenburg and E.M. Silvia, 'A coefficient inequality for Bazilevic functions', (Polish and Russian summaries), Ann. Univ. Mariae Curie-Sklodowska Sect. A 27 (1973), 5-12. 
[4] M.M. Elhosh, 'On a subclass of Bazilevic functions', Bull. A ustral. Math. Soc. 39 (1989), 167-170.

[5] A.W. Goodman, Univalent functions Vol. I (Mariner Pub. Co., Tampa, Florida, 1983).

[6] W.K. Hayman and J.A. Hummel, 'Coefficients of powers of univalent functions', Complex Variables 7 (1986), 51-70.

[7] M. Jahangiri, 'On the coefficients of powers of a class of Bazilevic functions', Indian $J$. Pure Appl. Math. 17 (9) (1986), 1140-1144.

[8] R.J. Leach, 'The coefficient problem for Bazilevic functions', Houston J. Math. 4 (6) (1980), 543-547.

[9] P.T. Mocanu, 'Une Propriete de convexite generalisee dans la theorie de la representation conforme', Mathematica 11(34) (1969), 127-133.

[10] J. Szynal, 'Some remarks on coefficients inequality for $\alpha$-convex functions', Bull. Acad. Polon. Sci. Ser. Sci. Math. Astronom. Phys. 20 (1972), 917-920.

[11] J. Szynal and S. Wajler, 'On the fourth coefficient for $\alpha$-convex functions', Rev. Roumaine Math. Pures Appl. 19 (1974), 1153-1157.

Department of Mathematics

University of California

Davis, CA 95616

United States of America 